\title{
Valence State Mapping of Iron Oxide Thin Film by Signal Processed ESI Series Energy-Loss Image
}

Ko-Feng Chen, Fu-Rong Chen and Ji-Jung Kai

Department of Engineering and System Science, National Tsing-Hua University, HsinChu, Taiwan 300, Republic of China

For the magnetic materials, the magnetic property is proportional to the angular momentum. In Electron Energy Loss Spectroscopy (EELS), the L ionization edges of transition metal usually display sharp peaks at the near edge region, known as "white line". The intensities of the white lines, normalized to the trailing background, reflect the filling of the $d$ states [1]. By signal processed electron spectroscopic imaging (ESI) series energy loss image [2], it is feasible to quantitative analysis of two-dimension $d$ states ratio $\left(\mathrm{d}^{2 / 3} / \mathrm{d}^{2 / 5}\right)$.

A set of signal processing methods comprising fast Fourier transformation interpolation and maximum entropy deconvolution has been successfully integrated to improve the equality of the extracted Fe L-edge spectra from ESI series. Fast Fourier transformation interpolation is used to improve the dispersion arising from discrete sampling of ESI series in the energy space. The maximum entropy method is used to dispel the convolution effect resulting from the ESI series acquired with a finite energy window. Figure (a) is the TEM image of $\mathrm{Fe} / \mathrm{\alpha}-\mathrm{Fe}_{2} \mathrm{O}_{3}$ and Figure 1(b) is the diffraction pattern of $\alpha-\mathrm{Fe}_{2} \mathrm{O}_{3}$ along the zone axis [10-10]. The $\alpha-\mathrm{Fe}_{2} \mathrm{O}_{3}$ was determined in upper layer according the diffraction pattern as shown in the Figure (b). The proposed signal processing methods are applied to extract the $\mathrm{d}$ state ratio from the ESI images in thea- $\mathrm{Fe}_{2} \mathrm{O}_{3}$. Figure 2 is the flow chart of signal processing procedures for reconstructing ESI spectra. The ESI images are acquired from $680 \mathrm{eV}$ to $780 \mathrm{eV}$, the energy slit is $4 \mathrm{eV}$ and the step is $2 \mathrm{eV}$, shown as Figure3 (a). Figure 3(b) and 3(c) are the spectrums extracted froma- $\mathrm{Fe}_{2} \mathrm{O}_{3}$ and $\mathrm{Fe}$ respectively. The L3 and L2 peaks are visible in the spectrum.

The advanced results will present in the conference.

Reference

[1] T. I. Morrison, N. J. Zaluzec, Phys. Rev. B, 32, p3107-3111.

[2] J. Y. Yan, F. R. Chen and J. J. Kai, J. Electron Microsc., 51, p391-400. 

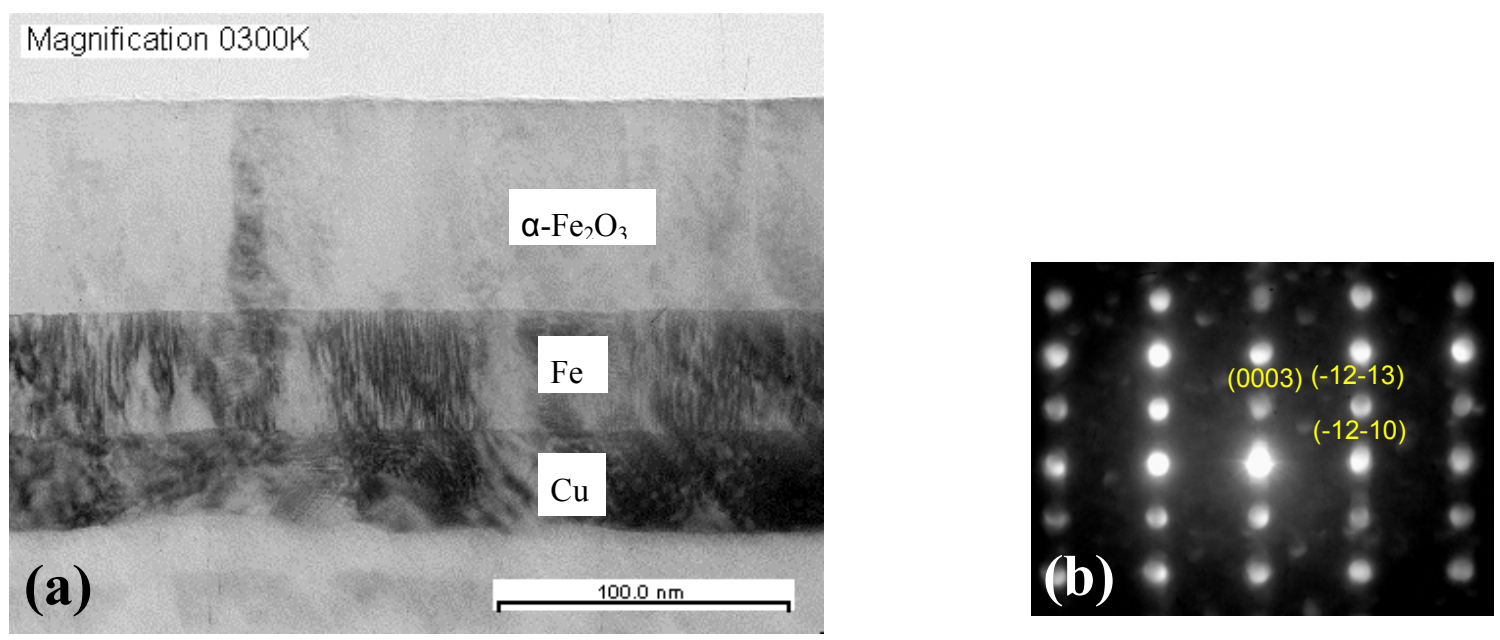

Fig.1(a) TEM image of the Fe/ $\alpha-\mathrm{Fe}_{2} \mathrm{O}_{3}$. Fig.1(b) The diffraction pattern ofo- $\mathrm{Fe}_{2} \mathrm{O}_{3}$.

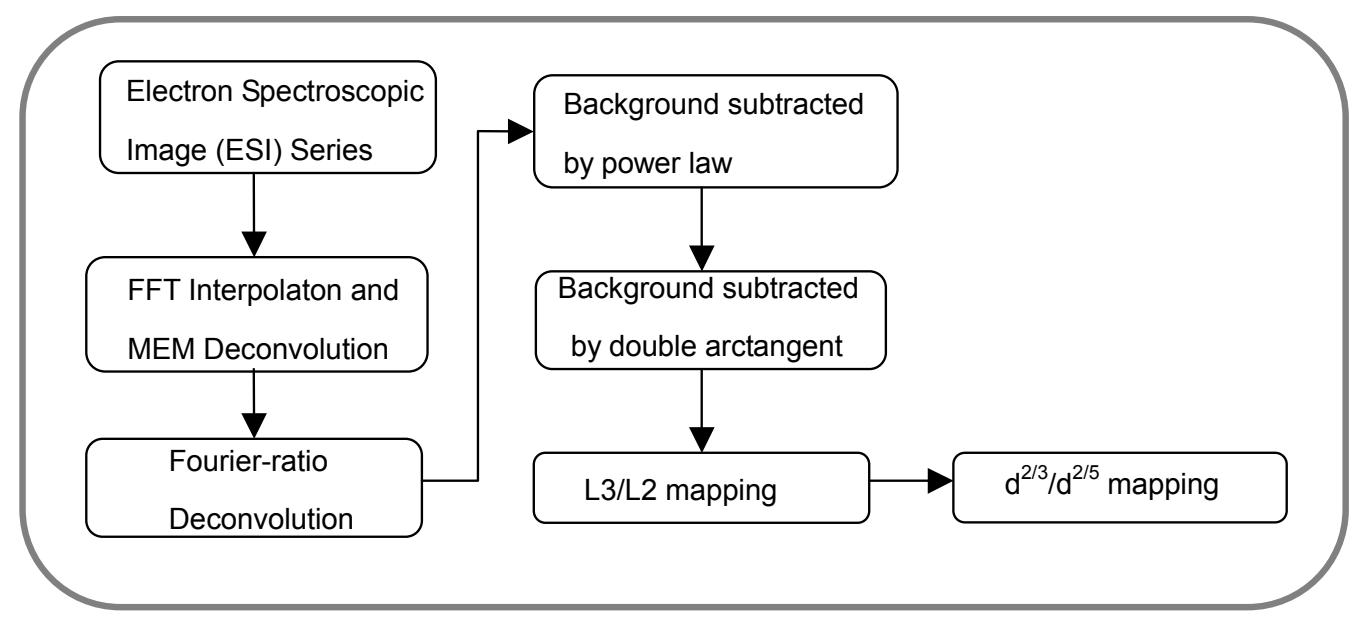

Fig.2 A flow chart of signal processing procedures for reconstructing ESI spectra.
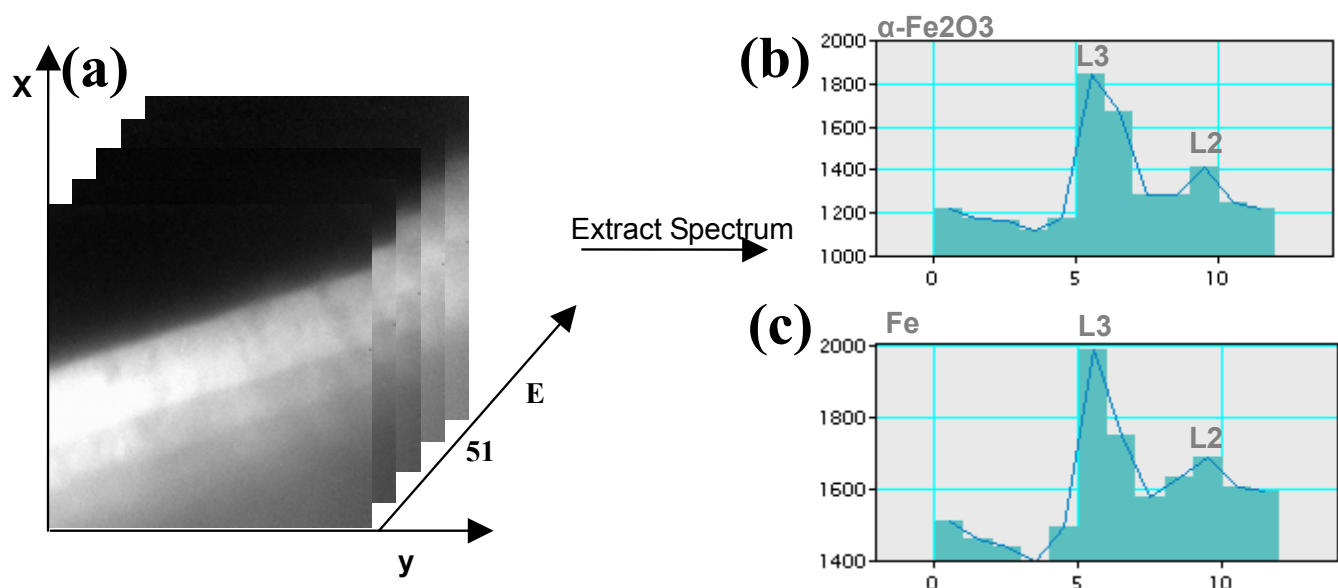

(c)

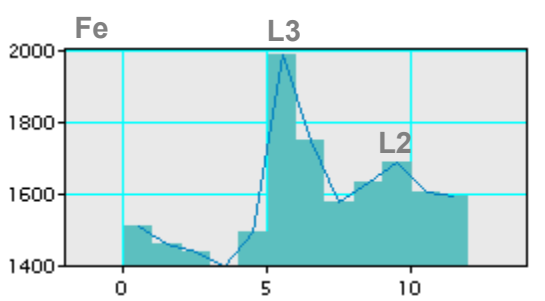

Fig.3(a) The ESI images acquired from $680 \mathrm{eV}$ to $780 \mathrm{eV}$. Fig3(b) and fig.3(c) are the spectrum extracted froma- $\mathrm{Fe}_{2} \mathrm{O}_{3}$ and $\mathrm{Fe}$ respectively. 